\title{
Figurações da Leitura: um estudo do papel do narratário em Grande sertão: veredas
}

\author{
Lisa Carvalho Vasconcellos
}

\begin{abstract}
Resumo
Em Grande sertão: veredas, vemos um narrador-protagonista relatar sua juventude a um desconhecido. O homem de fora que denominamos aqui narratário - já foi associado, sem muito desenvolvimento, a um protótipo de leitor, por parte significativa da crítica rosiana. É essa a analogia que pretendemos levar a cabo no presente trabalho, partindo da hipótese de que o estudo do papel desse narratário nos permitiria apresentar figurações da leitura.
\end{abstract}

Palavras-chave: Leitura. Guimarães Rosa. Roland Barthes.

De acordo com o Novo Dicionário da Língua Portuguesa (FERREIRA, 1986, p. 1023), leitor é aquele que percorre com a vista o que está escrito, aquele que decifra, reconhece e percebe palavras, ou ainda, aquele que depois de ver, junta as letras do alfabeto, repetindo-as mentalmente ou em voz alta. Em estado de dicionário, portanto, o ato de leitura é associado, sobretudo, a um fenômeno físico. Aqui, ler equivale a ver letras, juntá-las, recitá-las.

$\mathrm{Na}$ crítica especializada, entretanto, a noção de leitura torna-se bem mais complexa, para dar conta de um fenômeno cada vez mais amplo e multifacetado. Já em 1976, Barthes (Barthes, 1988, p. 44) nos alertava: "No campo da leitura não há pertinência de objetos: o verbo ler, aparentemente muito mais transitivo do que o verbo falar, pode ser saturado, catalisado, com mil objetos diretos: leio textos, figuras, cidades, rostos, cenas, gestos, etc.".

No que concerne à leitura literária, não é diferente. Determinados textos narrativos, poéticos ou dramáticos, pela sua abertura, forçam o leitor a adotar atitudes das mais variadas. Vale ressaltar que, nas últimas décadas do século $X X$, o foco da crítica se voltou justamente para esse assunto e o leitor passou a ganhar espaço nas teorizações que procuravam explicar o objeto literário. Ora, Guimarães Rosa, como um autor à frente de seu tempo, sempre demonstrou, em sua produção ficcional, preocupação com as questões relativas à recepção e Grande sertão: veredas é exemplar nesse sentido.

Esse livro, publicado em 1956, é estruturado na forma de uma narrativa em primeira pessoa, onde um velho jagunço reconta seu passado a um homem da cidade que vai visitá-lo. Embora a presença desse segundo seja indicada através de certos recursos narrativos, ele nunca toma a palavra, e o que podemos saber a respeito de sua pessoa vem filtrado pela voz do narrador. Resta a cada um de nós, leitores do livro, imaginar tudo aquilo que essa estranha personagem diz, faz e pensa, durante o 
tempo em que se dá a ação do romance. De maneira que, em nossas diferenças e singularidades, tornamo-nos nós o espaço de articulação dessa fala invisível, dando ao visitante a voz que a princípio não tem.

De fato, parece ter sido precisamente essa a proposta de Guimarães Rosa em Grande sertão: veredas. Já em nossas primeiras leituras desse livro, percebíamos que várias das frases de Riobaldo que faziam referência explícita ao homem de fora eram particularmente esclarecedoras quanto aos rumos do texto. Elas traziam reflexões de cunho metanarrativo, que poderiam ser entendidas enquanto pistas deixadas no romance para serem seguidas, mais tarde, pelo leitor. Pelo menos é essa uma das teses implícitas em "Grande sertão: veredas - a metanarrativa como necessidade diferenciada", ensaio de Lígia Chiappini (1998), que, dentre a vasta fortuna crítica de Rosa, foi uma das grandes fontes de inspiração para o presente trabalho.

Nesse artigo, a autora lista e classifica, em quatro grupos distintos, uma série de passagens nas quais o hóspede de Riobaldo é explicitamente mencionado. Um deles denominado metalingüístico - nos interessa particularmente. Nele, vemos passagens do texto que atraem o olhar do leitor para o processo de composição da narrativa. Revendo as citações que foram aí classificadas, temos uma boa amostra do que poderia nos servir de ponto de partida para a hipótese que queremos propor. Nelas, deparamos com colocações que, refletindo a respeito de diferentes aspectos da narrativa, poderiam ser entendidas como o esboço de uma problematização literária no âmbito das poéticas da modernidade. A oralidade, a memória e as dificuldades de transmitir a experiência vivida a outrem, por meio de um texto, são alguns dos temas aí encontrados:

Ai, arre, mas: que esta minha boca não tem ordem nenhuma. Estou contando fora, coisas divagadas. (ROSA, 2001, p. 37)

Contar é muito, muito dificultoso. Não pelos anos que já se passaram. Mas pela astúcia que tem certas coisas passadas - de fazer balancê, de se remexerem dos lugares. O que eu falei foi exato? Foi. Mas terá sido? Agora, acho que em não. (ROSA, 2001, p. 200)

[...] conto malmente. A qualquer narração dessa depõe em falso, porque o extenso de todo sofrido se escapole da memória. E o senhor não esteve lá. O senhor não escutou, em cada anoitecer, a lugúgem do canto da mãe-da-lua. O senhor não pode estabelecer em sua idéia a minha tristeza quinhoã (ROSA, 2001, p. 418).

Mas os trechos de Grande sertão: veredas listados por Lígia Chiappini (1998) que mais se assemelham a pistas deixadas ao leitor são aqueles em que o protagonista instrui seu hóspede na recepção de uma fala muitas vezes confusa ou subjetiva:

O senhor pode completar, imaginando. (ROSA, 2001, p. 67)

Eu sei que isto que estou dizendo é dificultoso, muito entrançado. Mas o senhor vai avante. (ROSA, 2001, p. 116)

[...] o senhor me ouve, pensa, repensa, e rediz, então me ajuda. (ROSA, 2001, p. 116)

Nas frases citadas acima, vemos ser atribuído ao visitante um papel muito semelhante ao de um leitor. Ambos recebem os fatos narrados, mas também os apelos daquele que narra, sendo convocados a pôr algo de seu no texto que lhes é transmitido. As falas do protagonista deixam explícita uma demanda de interpretação: a narrativa de Riobaldo precisa da atenção do homem de fora, da mesma maneira que um livro precisa de seu público para existir.

Fazendo um levantamento das principais idéias até agora propostas pela fortuna crítica rosiana em relação ao narratário, percebemos que a personagem do "senhor" misterioso vem intrigando os críticos desde a publicação de Grande sertão: veredas. 
Através dos anos, esse visitante de Riobaldo - ao qual, baseando-nos nas teorias de Genette (1972) e Prince (1980), denominamos narratário - vem assumindo os mais diversos papéis, segundo a interpretação que do livro se faz. Em nossa pesquisa sobre o assunto, vimos que ele foi aproximado, entre outros, a um aprendiz (UTÉZA, 1994), a um psicanalista (MENESES, 2002), a um agrimensor (SANTOS, 1981), a Deus (ROSENFIELD, 1993) e, até mesmo, ao famoso autor de Os sertões, Euclides da Cunha (BOLLE, 2004). Alguns trabalhos, entretanto, apontaram um caminho diverso. Eduardo Coutinho (1993), Francis Utéza (1994), João Adolfo Hansen (2000) e Lígia Chiappini (1998), por exemplo, sugeriram, sem muito desenvolvimento, uma analogia entre o narratário do romance e o leitor. Já Davi Arrigucci Jr. (1994), Benedito Nunes (1983) e Walnice Galvão (1986) são alguns daqueles que deslocaram a questão, propondo uma relação entre o "senhor" e o autor da obra.

Com base nessas leituras, torna-se impossível negar que, encenando metalingüisticamente 0 ato de produzir e receber um texto, o setting narrativo de Grande sertão: veredas implica necessariamente questões relativas à leitura. Nossa preocupação é saber que questões são essas e que resultados sua introdução no texto tem para nós, leitores. Duas perguntas em particular ocupam nossa mente: poderia ser o narratário, enquanto primeiro receptor da obra, uma referência para nós? E se assim fosse, que exemplos dignos de seu papel ele nos daria?

Instigados por essas perguntas passamos a uma investigação própria a respeito da personagem misteriosa. Começamos levantando as passagens em que Riobaldo, narrador do texto, explicita a existência de um visitante que o ouve. Percebemos, assim, que as alusões ao "senhor" eram feitas de maneiras diferentes e identificamos cinco recursos formais específicos usados nesse sentido pelo narrador: o velho jagunço faz uso de pronomes indicativos da segunda pessoa, vocativos e verbos no imperativo, para se dirigir ao narratário, questiona-o por meio de perguntas e, algumas vezes, conjuga verbos na primeira pessoa do plural, de modo a incluir o parceiro em suas ações. O resultado de tal pesquisa foi um total de 127 páginas copiladas com 1570 trechos retirados do livro. Mas se fazia necessário um recorte que transformasse esse material fragmentário e caótico em um conjunto apresentável ao leitor.

Recorremos, então, a Barthes e as suas proposições sobre o fragmento - que nos levaram, por sua vez, a noções de figura - para ressaltar, a partir do material levantado, as características mais importantes do narratário e as passagens do texto que as exemplificavam melhor. O texto escolhido foi Fragmentos de um discurso amoroso (2003). Nesse livro, o autor apresenta o tema do amor através de diferentes figuras, cada uma dedicada a um único topus da vida amorosa. Alguns exemplos são: "Fazer uma cena", "O ciúme", "A espera" etc. A estrutura de cada uma delas inclui um título, uma definição de poucas palavras do objeto em questão e três ou quatro notas que descrevem o problema. Aqui, referências literárias, filosóficas, místicas e psicanalíticas se misturam à experiência pessoal do autor em comentários sistematicamente numerados.

Com base nesse exemplo, chegamos nós mesmos a seis figuras de inspiração barthesiana, que procuram contemplar as principais características de nosso objeto de estudo. São elas: o viajante letrado, o neutro, o amigo, o estranho, o adversário e o árbitro. Infelizmente, dado o escasso espaço destinado a esse texto, será impossível dedicar a cada um desses itens o tempo que merece. Nos limitaremos a mencionar que cada um deles envolve um aspecto do nosso objeto de estudo. O viajante letrado trabalha com o fato de que o hóspede é um homem de fora. O neutro tem por tema seu silêncio. O amigo e o estranho envolvem aspectos do seu relacionamento com 
Riobaldo, que tanto pode ser íntimo, quanto pode revelar constrangimento. O adversário radicaliza essa segunda posição e lida com o aspecto de alteridade incorporado pelo narratário. Finalmente, o árbitro faz alusão à posição que o próprio protagonista - se confessando e procurando absolvição - a ele atribui.

Curiosamente, todas essas figuras lembram um pouco o papel do leitor no decorrer do processo de leitura. E, para nos aprofundarmos na relação narratário e leitor, fez-se necessário investigar algumas concepções do processo de leitura.

Do ponto de vista teórico, após estudar diversas abordagens sobre o tema, foi novamente Barthes quem nos forneceu idéias provocativas a respeito do ato de ler. Alguns podem argumentar que esse ensaísta francês não chegou a construir uma teoria sobre a leitura. Paradoxalmente, foi essa característica sua a que mais nos atraiu e estimulou a adotá-lo enquanto interlocutor. A leitura literária é um campo naturalmente criativo e não se encaixaria facilmente em um modelo pronto. Barthes parece reconhecer isso e não ambiciona abarcar o fenômeno integralmente através de ideais ou tipos que serviriam de modelo ao público leitor. Dele, aproveitamos, sobretudo, a idéia de que a leitura pode ser condutora do desejo de escrever. Ou seja, ser uma ação produtiva que não se esgota em si, mas que gera outras escritas (BARTHES, 1988).

Tendo em vista essa concepção de leitura, não foi difícil associar o narratário de Grande sertão: veredas ao leitor-produtor de Barthes. Aliás, não é sem razão que grande parte da fortuna crítica o associa ao autor do romance. De fato, não só ele escreve profusamente em sua cadernetinha durante toda a permanência na casa do narrador, como também interfere ativamente na narrativa de Riobaldo, fazendo com que esta seja fruto de um trabalho conjunto.

Mas buscamos dar um passo além, qual seja, associá-lo também às idéias do próprio Guimarães Rosa a respeito do processo de leitura. Isso se deu a partir da análise de documentos pessoais do autor, que indicam como ele idealizava a relação com seus leitores, a qual deveria incluir sempre o respeito e a amizade. Para Rosa, isso não significa, entretanto, que os receptores de sua obra devam se resignar a aceitar os sentidos que atribui para a mesma. Vimos que o autor confere grande autonomia a seus tradutores, por exemplo, insistindo que eles façam boa parte do trabalho de interpretação do texto. Observamos, ainda, que ele aceita as boas críticas, chegando a alterar seus escritos com base nas mesmas, e valoriza a identificação do leitor com o texto lido.

Várias das figuras não deixam de se associar às idéias de Barthes e de Guimarães Rosa sobre o ato de ler. Afinal, podemos ter, em relação a um texto, uma atitude neutra ou amigável, mas podemos também nos colocar contra suas idéias. Em qualquer dessas hipóteses somos sempre responsáveis por um julgamento, quer ele se refira ao valor daquilo que nos é contado, ou aos nossos próprios sentimentos a respeito. Quanto ao viajante letrado, é possível afirmar que ele pode ser identificado não apenas ao que propõem esses autores, mas ao que usualmente se concebe como um leitor mais "eficiente", isto é, aquele culto, erudito e sempre curioso, que se aventura em "viagens" através do texto que lê, até então desconhecido para ele.

Neutro é um leitor que evita aprovar ou condenar uma narrativa. Mas neutros podemos ser todos nós quando silenciamos nossa subjetividade para ouvir melhor a voz de um texto. Ou seja, quando abrimos espaço para que ele se articule dentro de nós. Em "A morte do autor", Barthes (1984, p. 70) afirma que

[...] um texto é feito de escrituras múltiplas, oriundas de várias culturas e que entram umas com as outras em diálogo, em paródia, em contestação; mas há um lugar onde essa 
multiplicidade se reúne, e esse lugar não é o autor, como se disse até o presente, é o leitor $[\ldots]$.

Sendo neutro, o narratário se aproxima, como postulou Barthes, menos de uma personagem concreta e mais de um espaço de articulação de sentidos.

Ao exigir a cooperação do "senhor" e descrever o mesmo como sendo um amigo, Riobaldo coloca em questão duas outras características do leitor. Este, não apenas segundo Barthes mas conforme um paradigma atual de recepção literária, ${ }^{1}$ tem uma interpretação ativa daquilo que lê e é muito possível que sinta empatia e se identifique com uma história envolvente. Mas se a relação do homem da cidade com seu anfitrião também inclui a discordância, a relação do leitor com o texto não foge a isso. Muitas vezes estranhamos um livro, discordamos do que lemos. Vimos que o próprio Guimarães Rosa valorizava tais desarmonias e freqüentemente propunha obras que, a princípio, incomodavam o público.

Quando escreve, um autor consciente ou inconscientemente é forçado a decidir o que, daquilo que tem para dizer, pode ou não ser publicado; o que é universal e o que é particular; o que pode fazer sentido para o público e o que faz sentido apenas para si mesmo. Para o escritor de uma obra, seu público representará, não raro, a alteridade. Esse é um outro aspecto do leitor que, em Grande sertão: veredas, também pode ser identificado ao doutor da cidade. Encarnando a alteridade demoníaca, esse estranho permite ser associado a uma descontinuidade, a uma quebra radical, a uma queda de nossos ideais, enfim, presente em alguns processos de leitura mais desestabilizadores.

Finalmente, quando lemos, naturalmente julgamos uma obra. E o texto, com o objetivo de influenciar tal julgamento, nos faz objeto de um jogo de sedução. As palavras de Barthes a respeito do leitor poderiam muito bem ter sido pronunciadas por Riobaldo em relação ao seu visitante:

[...] esse leitor é mister que eu o procure (que eu o 'drague'), sem saber onde ele está. Um espaço de fruição fica então criado. Não é a 'pessoa' do outro que me é necessária, é o espaço: a possibilidade de uma dialética do desejo, de uma imprevisão do desfrute: que os dados não estejam lançados, que haja um jogo (BARTHES, 1996, p. 9). ${ }^{2}$

Da ficção de Rosa, depreendem-se contribuições muito mais efetivas sobre a leitura do que as idealizadas pelo autor e mesmo do que as proposições instigantes de Barthes. Nela vemos instituído um modelo variado, plural de leitura, que tem resultados práticos na nossa recepção do texto. Não queremos dizer com isso que Rosa procura guiar nossa leitura de seu texto através de linhas mestras fornecidas pelo narratário. Muito pelo contrário, procuramos, e não achamos, no romance rosiano, caminhos que nos guiassem a uma interpretação segura do texto. Nesse sentido, poderíamos dizer que temos em Grande sertão uma leitura falha: falha como a vida de Riobaldo, que não experimentou em sua juventude o amor que ambicionava; falha como a narrativa elaborada por esse protagonista, que não foi capaz de recuperar seu passado perdido ou aliviar sua consciência; falha como rio que não chega ao mar, um rio baldo (LIMA, 1969, p. 71); falha como a escritura de Barthes que, segundo o próprio, não compensa nada, não sublima nada, (BARTHES, 2003, p. 161). Enquanto leitores do livro, somos herdeiros de todas essas faltas, nossa leitura não será nunca completa. Mas talvez seja justamente nesse hiato que uma nova escritura pode surgir. Resta-nos fazer como indicou Barthes e dar prosseguimento a essa aventura. 
Abstract

In Grande sertão: veredas, an old farmer named Riobaldo narrates his youth to a foreigner. A significant number of literary critics have compared the outsider - or narratee - to a prototypical reader. Nevertheless, none of them has investigated the matter thoroughly. That is what we intend to do.

Key words: Reading. Guimarães Rosa. Roland Barthes.

\section{Referências}

ARRIGUCI JR., Davi. O mundo misturado: romance e experiência em Guimarães Rosa. Novos estudos CEBRAP, São Paulo, n. 40, p. 7-29, nov. 1994.

BARTHES, Roland. Da leitura. In: _. O rumor da língua. Prefácio Leyla Perrone- Moisés. São Paulo: Brasiliense, 1988. p. 43-52.

Original francês.

BARTHES, Roland. Escrever a leitura. In: . O rumor da língua. Prefácio Leyla Perrone-Moisés. São Paulo: Brasiliense, 1988, p. 4042. Original francês.

BARTHES, Roland. Fragmentos de um discurso amoroso. São Paulo: Martins Fontes, 2003. 343 p. (Coleção Roland Barthes). Original francês.

BARTHES, Roland. A morte do autor. In: _. O rumor da língua. Prefácio Leyla Perrone-Moisés. São Paulo: Brasiliense, 1984, p. 6570. Original francês.

BARTHES, Roland. O prazer do texto. 4. ed. São Paulo:

Perspectiva, 1996. 86 p. (Coleção Elos). Original francês.

BOLLE, Willi. Grandesertão.br: o romance de formação do Brasil. São Paulo: Duas Cidades; Ed. 34, 2004. 480 p.

CHIAPPINI, Lígia. A metanarrativa como necessidade diferenciada. Scripta, Belo Horizonte, v. 2, n. 3, p. 190-204, $2^{\circ}$ semestre, 1998.

COUTINHO, Eduardo. Monólogo diálogo: a técnica híbrida do Grande sertão: veredas. In: __. Em busca da terceira margem: ensaios sobre o Grande sertão: veredas. Salvador: Fundação Casa de Jorge Amado, 1993. p. 61-70.

ECO, Humberto. Lector in fabula: a cooperação interpretativa nos textos narrativos. 2. ed. São Paulo: Perspectiva, 2002. 219 p. (Coleção Estudos). Original italiano.

FERREIRA, Aurélio Buarque de Holanda. Novo dicionário da língua portuguesa. 2. ed. rev. e aum. Rio de Janeiro: Nova Fronteira, 1986, p. 
GALVÃO, Walnice. As formas do falso: um estudo sobre a ambigüidade no Grande sertão: veredas. 2. ed. São Paulo: Perspectiva, 1986. 132 p. (Coleção Debates)

GENETTE, Gérard. Voix. In: Figures III. Paris: Seuil, 1972. p. 225267.

HANSEN, João Adolfo. O o: a ficção da literatura em Grande sertão: veredas. São Paulo: Hedra, 2000. 198 p.

LIMA, Luis Costa. Por que literatura. Petrópolis: Vozes, 1969.

MENESES, Adélia Bezerra de. Grande sertão: veredas e a psicanálise. Scripta, Belo Horizonte, v. 5 , n 10, p. 21-37, $1^{\circ}$ semestre, 2002.

NUNES, Benedito. A matéria vertente. Seminário de ficção mineira: de Guimarães Rosa aos nossos dias, Belo Horizonte, n2, p. 9-29. 1983.

PRINCE, Gerald. Introduction to the study of the narratee. In: TOMPKINS, Jane P. (Org.). Reader response criticism: from formalism to post-structuralism. Baltimore: The John Hopkins University Press, 1980. p. 7-25.

REY-DEBOVE, Josette (Org.). Dictionnaire du français: référence apprentissage. Paris: CLE International, 1999.

ROSA, João Guimarães. Grande sertão: veredas. 19. ed. Prefácio de Paulo Rónai. Rio de Janeiro: Nova Fronteira, 2001, 624 p.

ROSENFIELD, Kathrin. Os descaminhos do demo: tradição e ruptura em Grande sertão: veredas. Rio de Janeiro: Imago; São Paulo: EDUSP, 1993. 217 p. (Biblioteca Pierre Menard)

SANTOS, Lívia. A unidade romanesca de Grande sertão: veredas (III): A crise do discurso narrativo. Suplemento Literário de Minas Gerais. Belo Horizonte, v.14, n. 759/760, p. 6, abr. 1981.

UTÉZA, Francis. João Guimarães Rosa: metafísica do Grande sertão. São Paulo: EDUSP, 1994. 536 p. Original francês.

$\prod_{1}$

para dar um exemplo de como tal atitude está em consonância com as modernas teorias sobre a leitura tomemos como exemplo o clássico de Umberto Eco sobre o assunto, Lector in fabula (2002), que tem o subtítulo de: "a cooperação interpretativa nos textos narrativos".

2 Segundo o dicionário francês Le Robert, o verbo draguer, utilizado no original por Barthes, pode ser definido, em um sentido familiar, como: "Chercher à lier connaissance avec (qqn) pour avoir une aventure amoureuse" (REY-DEBOVE, 1999, p. 314). Em outras palavras: procurar fazer contato com alguém para ter uma aventura amorosa, paquerar. 